\title{
The Quality of Training Future Teachers during the COVID-19 Pandemic: A Case from TNPU
}

\author{
Mariya Boyko ${ }^{1}$, Olha Turko ${ }^{1}(\mathbb{D})$, Oleksandr Dluhopolskyi ${ }^{2,3, *(\mathbb{D})}$ and Halyna Henseruk ${ }^{4}(\mathbb{D})$ \\ 1 Faculty of Pedagogy and Psychology, Ternopil Volodymyr Hnatiuk National Pedagogical University, \\ 46027 Ternopil, Ukraine; maryboyko@tnpu.edu.ua (M.B.); o.turko@tnpu.edu.ua (O.T.) \\ 2 Faculty of Economics and Management, West Ukrainian National University, 46027 Ternopil, Ukraine \\ 3 Faculty of Hystory, Ternopil Volodymyr Hnatiuk National Pedagogical University, 46027 Ternopil, Ukraine \\ 4 Faculty of Physics and Mathematics, Ternopil Volodymyr Hnatiuk National Pedagogical University, \\ 46027 Ternopil, Ukraine; genseruk@tnpu.edu.ua \\ * Correspondence: o.dluhopolskyi@wunu.edu.ua or dlugopolsky77@gmail.com
}

Citation: Boyko, M.; Turko, O.; Dluhopolskyi, O.; Henseruk, H. The Quality of Training Future Teachers during the COVID-19 Pandemic: A Case from TNPU. Educ. Sci. 2021, 11, 660. https://doi.org/10.3390/ educsci11110660

Academic Editors: Serhii Stepenko, Nataliia Stukalo and Asnate Kažoka

Received: 31 August 2021

Accepted: 14 October 2021

Published: 20 October 2021

Publisher's Note: MDPI stays neutral with regard to jurisdictional claims in published maps and institutional affiliations.

Copyright: (C) 2021 by the authors. Licensee MDPI, Basel, Switzerland. This article is an open access article distributed under the terms and conditions of the Creative Commons Attribution (CC BY) license (https:// creativecommons.org/licenses/by/ $4.0 /)$.

\begin{abstract}
This article describes the experience of the communicative competence formation of future teachers in a blended form of education as a dominant one in the period of the COVID-19 pandemic. The main features of such terms as "education quality" and "communicative competence" are revealed; the peculiarities of their components and structure are described. Using the results of a survey the authors draw conclusions about the advantages and disadvantages of online and offline learning and the efficacy of technical learning tools. The article also describes the educational platforms and technical means most frequently used by teachers and students in their everyday life. The results of testing in philological and linguodidactic disciplines after online and offline learning are presented in the paper. Conclusions are made concerning the peculiarities of online and offline training by means of Moodle and Google Classroom learning platforms, as well as Viber, Telegram, Email, Zoom Cloud Meetings and other platforms. Considering the results of the survey of students on the usage of technical means in online learning, the authors provide suggestions on improving the quality of training future teachers. The discussion part of the article presents the questions for discussion concerning a blended form of training as an effective one during the COVID-19 pandemic. The conclusion states the advantages and disadvantages of mixed forms of learning.
\end{abstract}

Keywords: distance learning; blended learning; communicative competence; quality of education

\section{Introduction}

Nowadays, both the individual and the state, which acts as a guarantor of national interests, are interested in a high quality of educational services. The quality of education depends on the activity of a learner, on the desire of each student to develop and selfimprove and on their ability and willingness to use the acquired knowledge in practice.

Experts distinguish three components of quality [1]: the quality of education (the formation of professional competencies); the quality of teaching and upbringing methods (the organization of educational activities, and motivation for cognitive activity, as well as control, and evaluation processes); and the quality of personal education (the formation of a system of values, and the ability to obtain moral norms, for example). The quality of education is determined by the evaluation system. It is due to the needs of all people interested in the education market (students, academicians and professors, employers, the state, and society). The more accurate the evaluation, the more successful the education. The effectiveness of the system for assessing the quality of training will provide consumers with educational services that a higher educational institution can provide by improving the management structure, increasing productivity, optimizing costs, and strengthening the image and position on the educational services market.

The determinants of the higher education system-for example, mobility, computerization, dynamism, and globalization, have led to a revision of the tools of the learning 
process. Firstly, communicative competence is defined by the world community as a priority among the dominant competencies of the 21st century for lifelong learning [2]. Secondly, the requirements for future professionals in various fields have changed, namely, the emphasis is put on the ability to learn throughout life, acquire new knowledge and develop skills for work, for an interesting, healthy, dignified, and common life [3]. Thirdly, modern young people, who, according to the "theory of generations" are called "generation Z" or "digital people", are characterized by other psychological and mental traits [4]. They have a noticeable tendency toward individualism, self-confidence and a focus on success. This generation needs cooperation and partnership, encouragement, and praise, it is characterized by mobility and self-discipline. These young people will learn if they understand the purpose of learning. Fourthly, the COVID-19 pandemic forced the world community to radically change the way of daily life and influenced the organization of the learning process: blended learning with a distant form was the dominant mode of learning. Undoubtedly, the form of learning should not in any way affect the quality of the learning process and its effectiveness.

The tasks of the article are: (1) to analyze the scientific literature concerning the communicative competence and quality of education and define the main features of these terms; (2) to experimentally test the effectiveness of distance learning tools; (3) to compare different levels of communicative competence whilst learning online and offline; and (4) to formulate conclusions about the tools of forming the communicative competence of future teachers in blended learning.

\section{Literature Review}

The issue of an effective learning process during the COVID-19 pandemic is becoming a pivotal one. The published articles are mainly theoretical articles based on literature reviews. The current study results revealed that articles focusing on COVID-19 were subject to an exceptionally rapid editorial review before publication. In this context, it may be said that the editors of international journals have a clear responsibility to pass COVID-19-focused articles through a healthy referee process to protect the publication standards of their journals and to uphold the ethics of the scientific study [5].

At the same time, the question of how to form any competence using distance and blended learning methods, becomes relevant. Blended learning is a " ... mixed learning paradigm that integrates e-learning with traditional learning theories and practices, materialized in a flexible, multimodal, and multilinear redesign that promotes self-regulation and collaborativeness" [6].

Let us theoretically outline the meaning of the concept of "communicative competence" and, through experimental research, identify the effective means of its formation during the COVID-19 pandemic. Vatuitniev was the first to introduce the term "communicative competence" in linguodidactics. The scholar defined communicative competence as the "... selection and implementation of the program of speech behavior depending on a person's ability to navigate in communicative situations and classify situations depending on topics, tasks and communicative guidelines" [7].

The structure and content of communicative competence have been studied by Ukrainian [1,4,8-10] and foreign scholars [11-16]. According to Chomsky, " ... communicative competence is a much more inclusive category than linguistic competence" [17]. Based on the studies [8-17], the following components of communicative competence can be distinguished:

- An understanding of various communication situations, which is based on the knowledge and life experience of a person;

- The ability to effectively interact with the environment through an understanding of oneself and others in a constant change of mental states, interpersonal relationships and social conditions;

- The self-understanding of a person-their own psychological potential, the potential of a partner, and the situation itself; 
- The readiness and ability to find contact with people;

- Inner means of regulating communicative actions;

- Knowledge, skills and abilities to communicate constructively;

- The inner resources necessary to construct effective communication in a range of situations of interpersonal interaction.

As competence is a quality acquired thanks to situations through which we live as well as a reflection of our experience, we think that communicative competence can be formed with the help of its components such as knowledge, skills, abilities, behavioral stereotypes and efforts [18].

Knowledge in communicative competence comprises linguistic facts, which should be constantly updated and deepened. Skills are the mastery of means and methods of the selection of the normative equivalent during a speech activity. For example, knowing the paradigm of the declension of nouns, the speaker, having determined the declension and group of nouns, correctly chooses the ending. The means used here are spelling rules, and the method is a word change by changing its endings. Abilities are innate qualities to perform a specific task and are manifested in different ways. A significant role is played by language skills developed in school and the motivation of students to improve them. Behavioral stereotypes are a communicative portrait of a teacher, and the observance of ethical norms in communication both in the classroom and outside it. Moreover, in our opinion, it is advisable to detect the speech errors of students in the most tolerant form, indicating the ways to eliminate them. The behavioral stereotype is determined by socio-cultural norms, as well as extralinguistic and prosodic means of communication. In pedagogy, the stereotypes of behavior should correlate with the types of roles of a modern teacher, such as: facilitator, tutor, coach, supervisor, moderator and mentor. Efforts as a conscious use of mental and physical resources for a specific purpose [18] should be stimulated by motivation to improve the culture of speech, the means of evaluation (for example, oral approval, encouragement, and adding or reducing grades for other educational activities) and involvement in group projects.

Therefore, communicative competence appears to be a structural phenomenon that contains values, motives, attitudes, socio-psychological stereotypes, knowledge, skills and abilities as its components. To develop communicative competence, it is necessary: to define the concept and structure as well as the content for different age stages; to apply a systemic approach, to ensure the interaction of different people, areas and technologies in order to achieve favorable results; and to choose a method, to develop programs, directions, technologies and techniques to form communicative competence.

The following tasks of forming the communicative skills of students have been formulated taking into consideration verbal-communicative competence [19]: to ensure the language environment for students; to make sure communicative situations are created and students have communicative practice; to guarantee the acquisition of lexical units, grammar forms, syntactic constructions and logical connections of students; to activate the use of vocabulary units and grammar constructions; to ensure that all necessary abilities in the sphere of speech development are formed; to conduct constant work connected with the language development and professional field-related classes whilst practicing the skills of students in grammar, vocabulary, reading, and listening; and the atmosphere of competitiveness for a high level of communication and the implementation of demands concerning speech correctness.

Thus, communicative competence is the ability of a person to express and interpret concepts, thoughts, feelings, facts, and views orally and in written form (through listening, speaking, reading, writing, and by using multimedia means) with the help of language knowledge and a system of mental and behavioral characteristics. 


\section{Materials and Methods}

A total of 160 students of the Faculty of Pedagogy and Psychology of Ternopil Volodymyr Hnatiuk National Pedagogical University (TNPU) took part in this experimental research. The experimental study was conducted during the 2020-2021 academic year.

The experimental teaching means used in the language and speech training of future teachers consisted of the following components: (1) tests for the self-acquisition of knowledge (the tests contained both multiple choice tests (students had to choose the correct answer from the suggested ones) and creative tasks); (2) individual project tasks; (3) teaching methods and technologies (interactive technologies, the development of critical thinking through the use of "discussion" methods, "brainstorming", and Bloom's taxonomy); and (4) Moodle and Google Classroom learning programs (LMS) and the Zoom platform for video-conferencing (VCT), Telegram multiplatform cloud messenger and other ICT tools.

The experimental research comprised three stages. At the ascertaining stage, we studied the peculiarities of forming the communicative competence of future teachers in pedagogical theory and practice, attended classes of our colleagues, talked to students, and conducted a SWOT-analysis. At the formative stage, in accordance with the organization of the learning process at the university, several students were studying via a distant mode, whereas others were learning offline. This training format was organized to comply with the anti-epidemic measures connected with the COVID-19 pandemic. Students constantly changed the mode of study from offline to online and vice versa at one-week intervals. At the final stage, control tests were conducted to verify the effectiveness of the teaching methods used in the offline and online modes. Therefore, we conducted a qualitative and quantitative analysis of the results of the study, and determined the effectiveness of the applied learning approaches in forming the communicative competence.

The levels of the methodological knowledge and skills of the participants were measured by the formula [19]:

$$
\mathrm{K}=\mathrm{A} / \mathrm{N}
$$

where $\mathrm{K}$ is the coefficient of the learning outcomes, $\mathrm{A}$ is the number of points obtained for correct answers, and $\mathrm{N}$ is the maximum number of points assigned for correct answers. Learning outcomes of 0.7 and above were considered acceptable according to Cronbach's alpha reliability factor [20].

\section{Results}

The formation of the communicative competence of future teachers was conducted during the following courses:

- "The Ukrainian language (for professional purposes)". The learning outcomes of this course provided a mastery of the norms of modern Ukrainian literary language; the peculiarities of conducting a business conversation; the basic requirements for business documents; the correct use of different language tools in accordance with communicative intentions; and the apt expression of opinion to successfully solve problems and tasks in teaching activities.

- "Workshop on the development of coherent speech". The learning outcomes of this course provided a mastery of the skills to reveal the topic of the text; the collection and systematization of material; the proofreading of the written text; the expression of thoughts in a grammatically correct way; the mastery of the theoretical and methodological foundations of work on coherent speech; the spelling features of the language design of the text, as well as utterances; the means of communication in texts and the linguistic features of speech styles; and the ethical rules of communication.

- "Literary editing". The learning outcomes of this course provided the formation of knowledge about the methodological principles of literary editing; text composition; the mechanisms to find and eliminate errors in the text; the possibilities of lexical and grammatical and stylistic means of a language; the ability to perform a literary 
analysis of the text; a logical analysis of the text; the evaluation of the composition in terms of its integrity, and relevance to the theme, as well as the intention, of the author and the genre of the work; the expediency, and completeness as well as the reliability of facts in the text; and the ability to work with lexical and grammatical as well as stylistic means of speech to improve the text.

- "Educational technologies of teaching language and literature in a primary school". The learning outcomes of this course provided a mastery of the theoretical principles of innovative technologies for teaching the Ukrainian language and reading in primary school and the application of pedagogical technology during lessons in primary schools considering the individual characteristics of students and the peculiarities of the pedagogy of partnership.

- "Foreign language teaching methods". The learning outcomes of this course were a knowledge of the peculiarities of the learning process in a foreign language in primary schools according to the Concept of the New Ukrainian School, standard educational programs for grades 1-2, and 3-4; the possession of skills of methodical activity on teaching, and education, as well as upbringing and developing primary school students in both the classroom and extracurricular work in a foreign language; and the formation of the ability to implement professional (project, adaptational, organizational, motivational, communicative, research and control) functions of a foreign language teacher in primary schools.

The pilot study began during the introduction of quarantine measures in Ukraine in March 2020 due to the coronavirus disease. Distance learning was the only form of education at the university. Between September and October 2020, the university worked only offline, and from November to December 2020, the students were studying online. Based on the results of distance learning, we interviewed 160 students.

The generalized results of the survey are as follows (Figure 1). Among the resources used by students during distance learning, the most popular were Zoom (used by $96 \%$ of respondents), Moodle (used by $93 \%$ of respondents), email (used by $83 \%$ of respondents) and Google Classroom (used by $26 \%$ of respondents). Telegram and YouTube were also popular among the respondents.

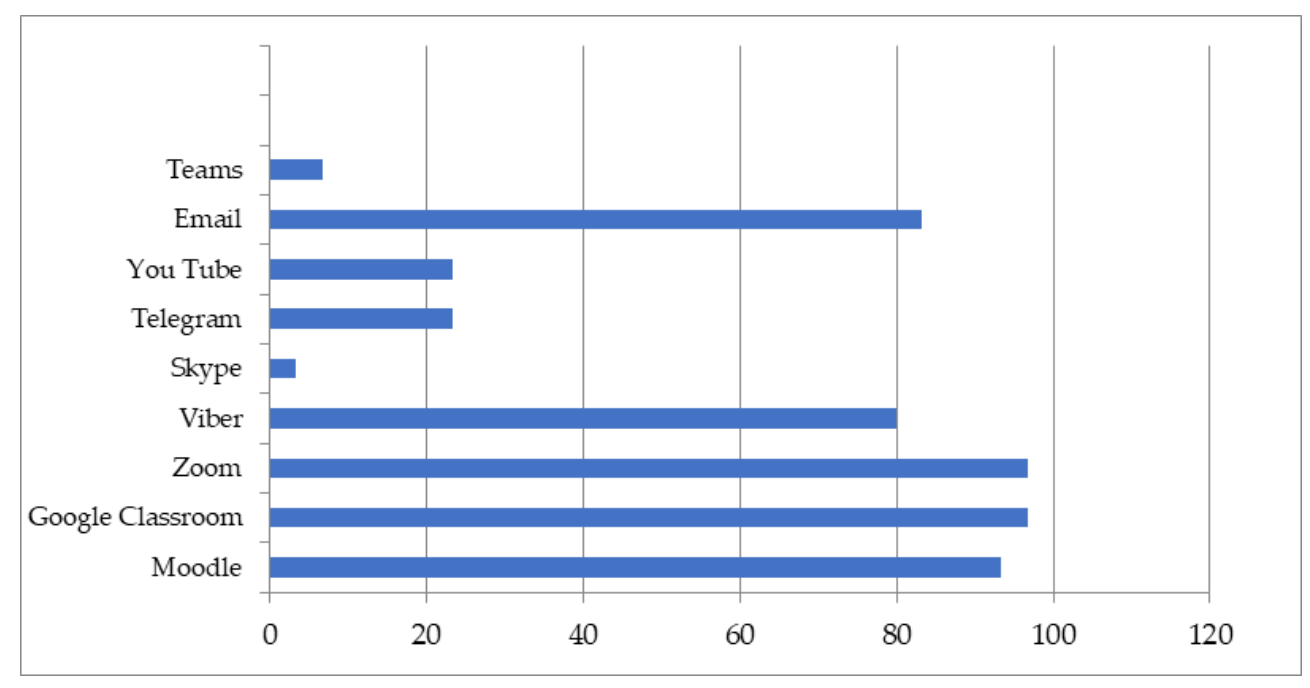

Figure 1. Distance learning resources. 
The results of the questionnaire (Figure 2) showed that the absence of constant Internet access $(33 \%)$, inconvenience in using distance learning platforms $(26 \%)$ and the absence of clear requirements for the tasks $(26 \%)$ were the most widespread difficulties that students had to face in the process of distance learning. It should be noted that $43 \%$ of respondents said that they did not experience any difficulties. Other difficulties included a lack of necessary skills to work with the equipment (23\%) and a lack of necessary equipment at home $(10 \%)$.

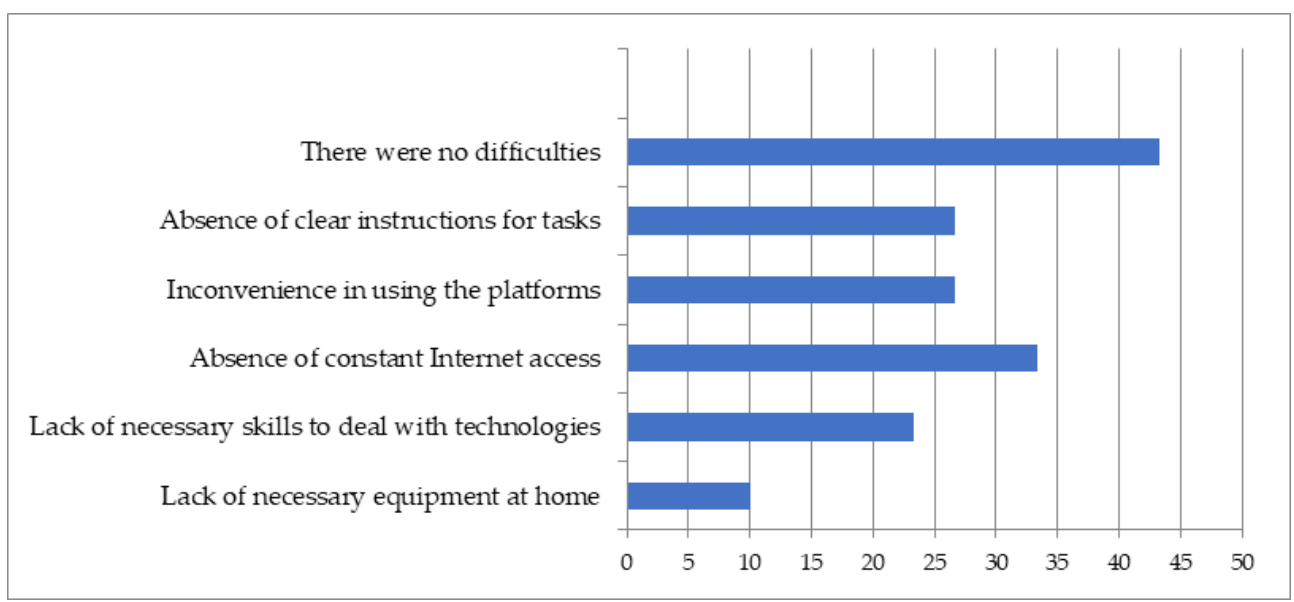

Figure 2. Distance learning difficulties.

Extremely negative indicators were observed in the hours of preparation for distance learning. More than $50 \%$ of the respondents said they spent more than two hours preparing for their lessons. A total of $20 \%$ of the respondents answered that it took them $1-2 \mathrm{~h}$ to prepare for a distance lesson and 16-60 min were spent by $17 \%$ of the respondents. A total of $6 \%$ of the respondents spent less than $30 \mathrm{~min}$ on their preparation (Figure 3 ).

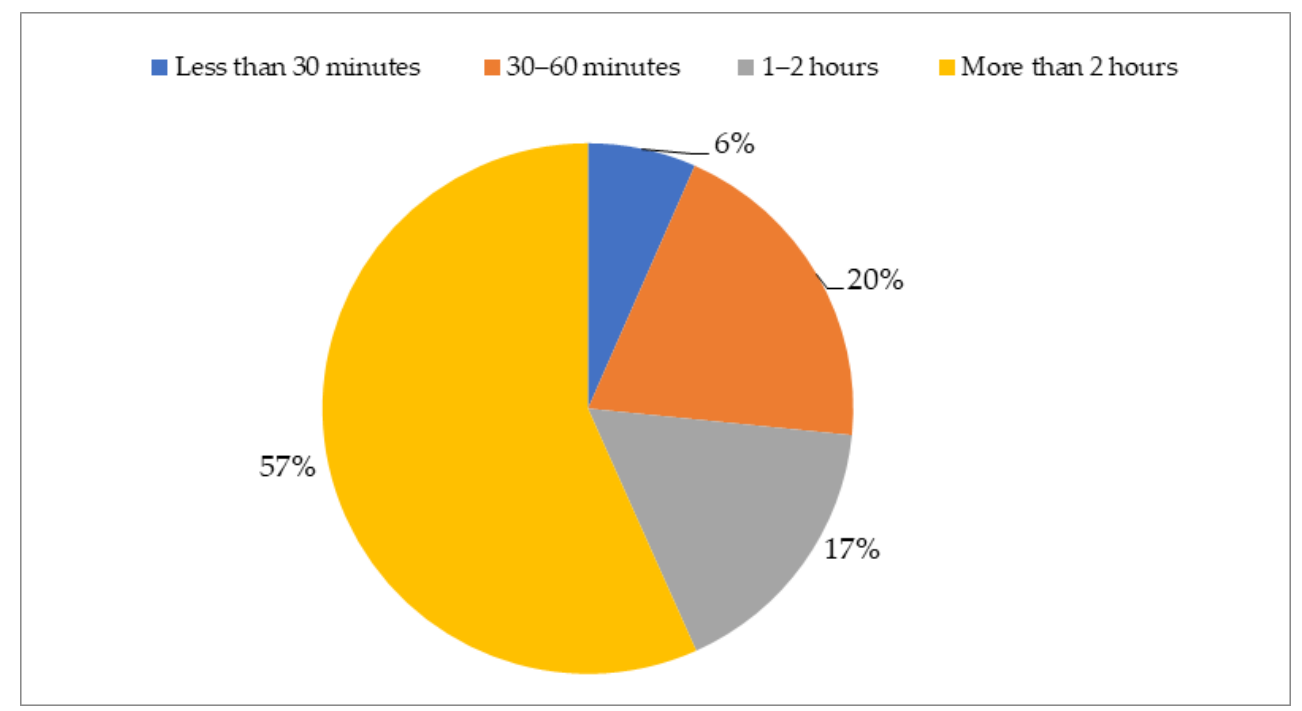

Figure 3. Allocated time for distance learning preparation.

On average, for $43 \%$ of the respondents it took an hour or two to communicate with teachers/students. A total of $23 \%$ of those surveyed said that communication with teachers/students took no more than $2 \mathrm{~h}$. A total of $17 \%$ of the students stated that they communicated with teachers/students for 30-60 min. The rest (17\%) communicated with teachers/students for less than $30 \mathrm{~min}$ a day (Figure 4). 


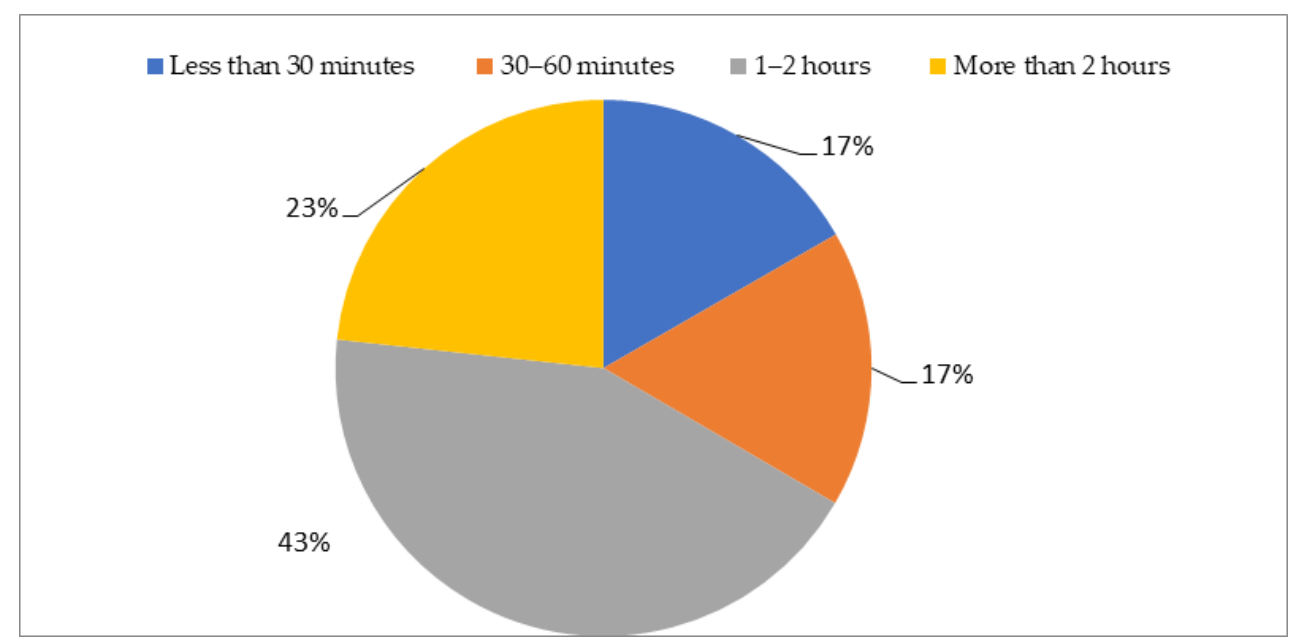

Figure 4. Allocated time for communication with teachers/students.

A total of $20 \%$ of the respondents were completely satisfied with the preparation of teachers/students for online classes. The largest part (57\%) said that they were rather satisfied with the training. Of those interviewed, $13 \%$ mentioned that it was difficult for them to answer this question. A total of $10 \%$ of the respondents were rather dissatisfied with the quality of training. There were no people who were completely dissatisfied with the level of preparation of teachers for online classes, which is a very good result (Figure 5). More than half of the respondents preferred traditional learning (66\%); the other $33 \%$ preferred distance learning (Figure 6).

Considering the content of communicative competence, we checked the level of its formation during online and offline classes. According to the results of offline learning, we interviewed 160 students. During offline learning, the most frequently used technical tools were email (which served as a means of obtaining exam results), tests, and Moodle as a platform for the learning process. The use of these tools demonstrated the impartiality of teachers in assessing the results of the achievements of students (Figures 7 and 8).

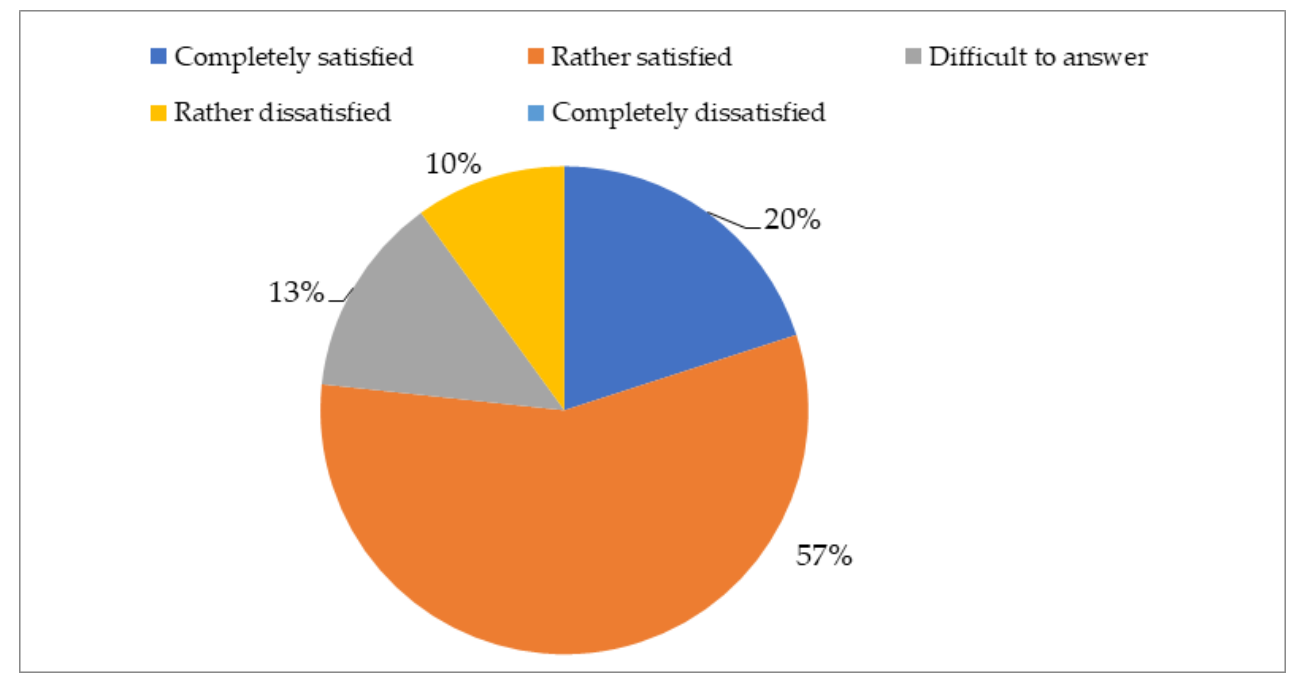

Figure 5. The level of satisfaction of students/teachers with the preparation for online classes. 


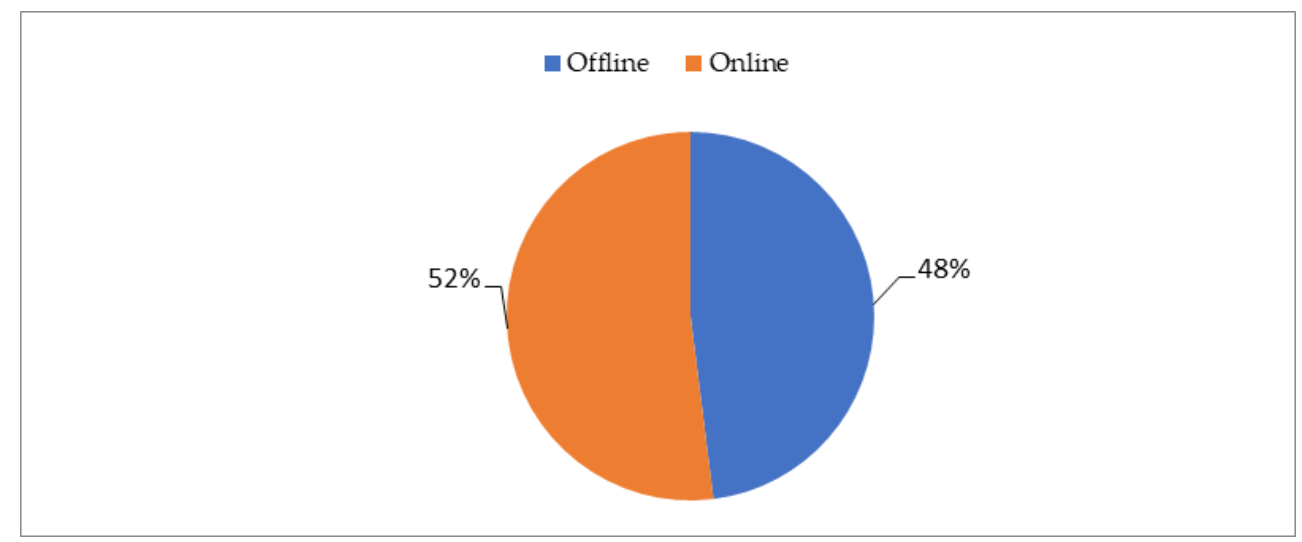

Figure 6. Which form of learning is better: online or offline?

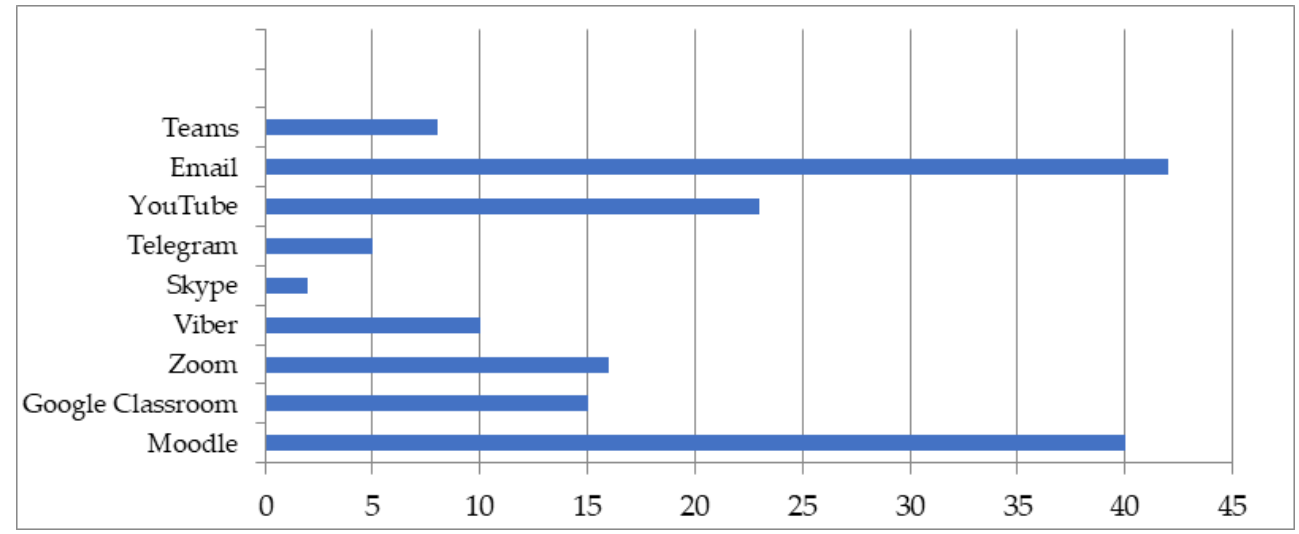

Figure 7. Technical training resources.

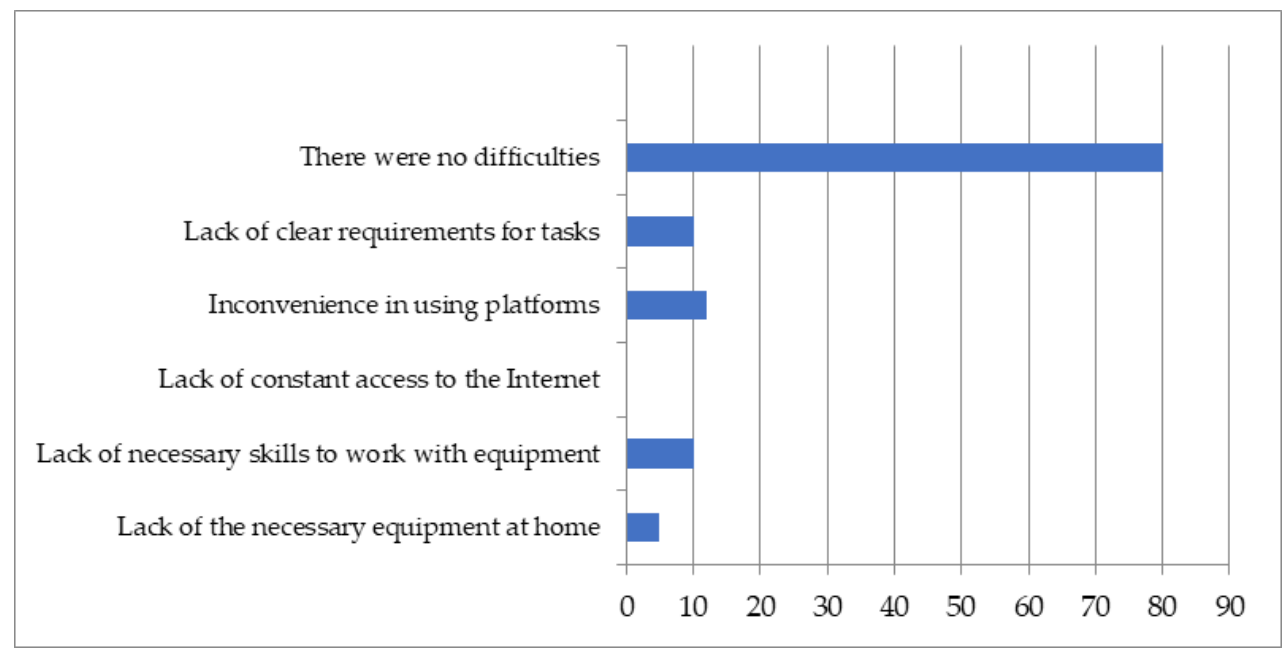

Figure 8. Using the technical teaching tools.

As students used technical aids in offline learning at the university, where there was a strong internet network and there were assistant engineers in computer classes, there were fewer difficulties with technical tools than during online learning (Figure 9). 


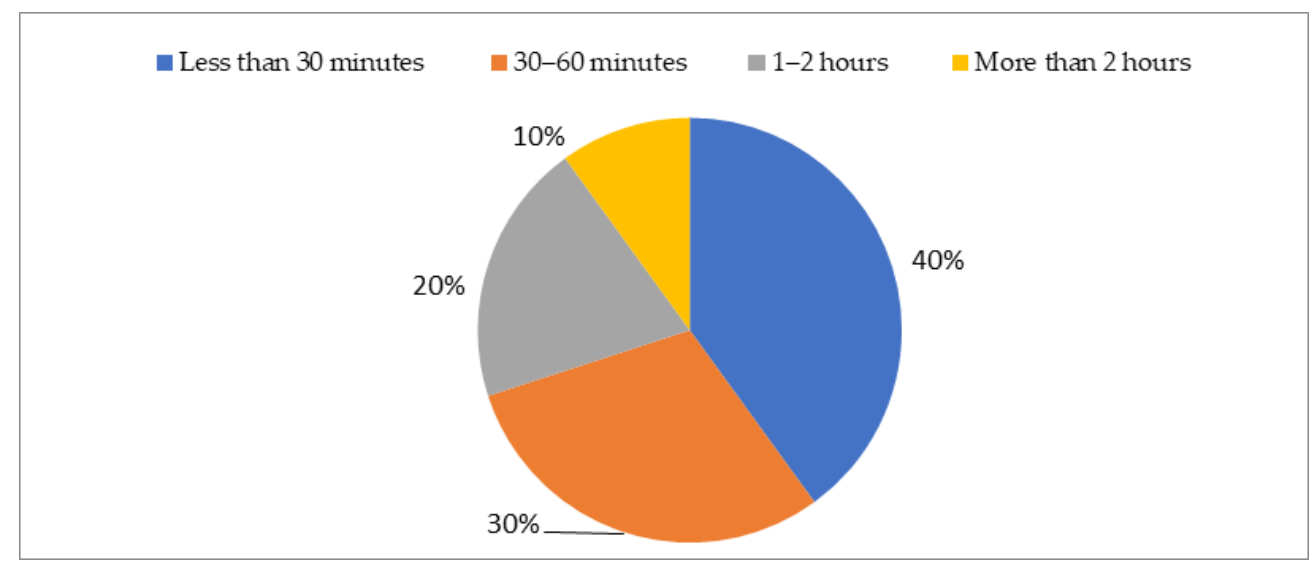

Figure 9. Allocated time for distance learning.

The time for distance learning was significantly reduced as students had the opportunity to communicate more with each other and with teachers as well (Figure 10).

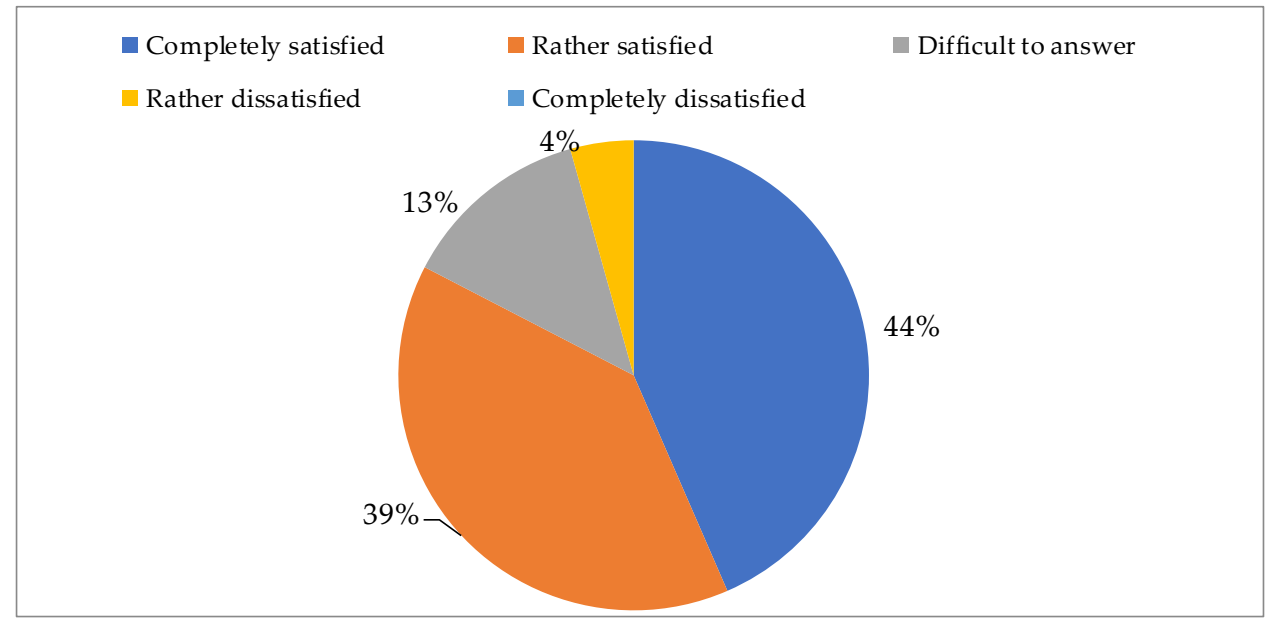

Figure 10. Are students satisfied with the technical support of training?

Having experienced the two modes of learning-online and offline-the students preferred the latter (Figure 11). Among the comments, the opportunity to communicate with teachers and classmates in a relaxed atmosphere, and the emotionality of communication prevailed.

Online learning, according to the respondents, also had its advantages namely, a significant saving of the time needed to get to university, and the possibility of having longer breaks for rest after classes.

We compared the results of the mid-term tests in the disciplines aimed at forming communicative competence and present them in the Table 1 . The analysis of the results in blended learning revealed that skills (the practical component of communicative competence) were better formed in offline learning, whereas abilities, in online learning. Obviously, during distance learning, students themselves were able to better demonstrate their abilities because teachers performed the roles of learning partners and did not impose any algorithms for solving learning problems.

The suggestions of students to improve distance learning were rather interesting: to buy a Zoom Pro license in order to not have restrictions on distance learning; to conduct training and courses for students and teachers on how to use technical teaching tools; to develop mobile applications for learning; and to strengthen the psychological assistance to students for them to adapt to distance learning. 


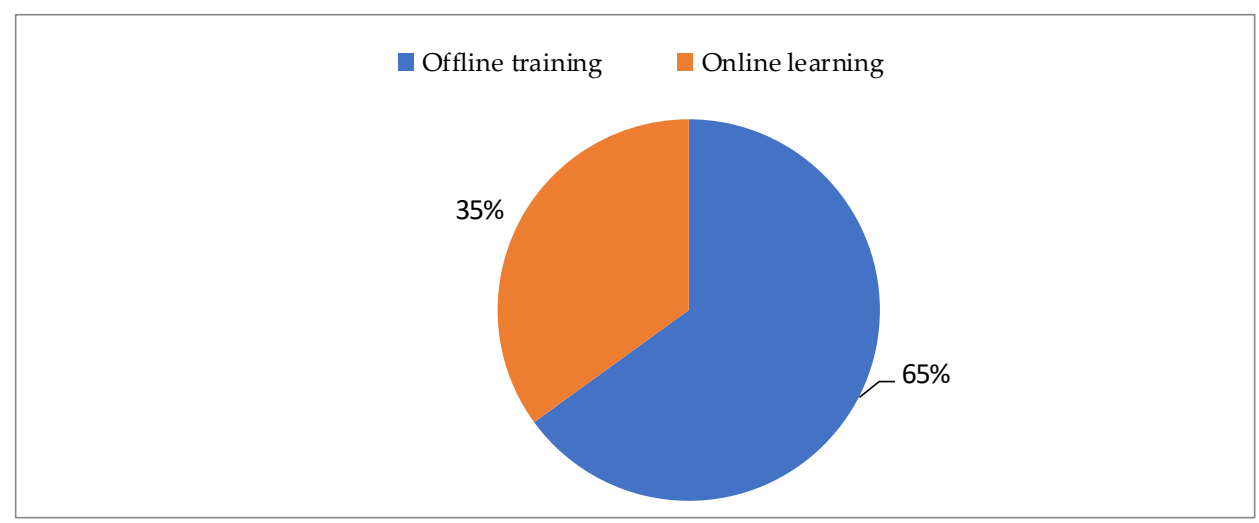

Figure 11. Which form of learning is better: online or offline?

Table 1. The level of communicative competence of students when blended learning is used.

\begin{tabular}{|c|c|c|c|c|c|}
\hline \multirow{3}{*}{$\begin{array}{l}\text { Communicative } \\
\text { Competence }\end{array}$} & \multirow{3}{*}{ Tools } & \multicolumn{4}{|c|}{ Learning Format } \\
\hline & & \multicolumn{2}{|c|}{ Online Learning } & \multicolumn{2}{|c|}{ Offline Training } \\
\hline & & $\%$ & $\begin{array}{c}\text { Number of } \\
\text { Students }\end{array}$ & $\%$ & $\begin{array}{c}\text { Number of } \\
\text { Students }\end{array}$ \\
\hline Knowledge & $\begin{array}{l}\text { Reproductive-search tests (with } \\
\text { one/several correct answers, the } \\
\text { correspondence between the task and } \\
\text { the answers, one answer from several } \\
\text { suggested) }\end{array}$ & 25 & 40 & 26 & 42 \\
\hline Skills & Independent research task ${ }^{1}$ & 31 & 50 & 38 & 60 \\
\hline Abilities & Project work of students ${ }^{2}$ & 24 & 38 & 19 & 30 \\
\hline $\begin{array}{l}\text { Behavioral } \\
\text { Stereotypes }\end{array}$ & Pedagogical skills of a teacher ${ }^{3}$ & 10 & 16 & 12 & 20 \\
\hline Effort & Adherence to the training schedule ${ }^{4}$ & 10 & 16 & 5 & 8 \\
\hline
\end{tabular}

${ }^{1}$ Writing an essay on a given topic, linguistic and stylistic analysis of the text, application of pedagogical technologies during the lesson, text editing, translation of a scientific article, text arrangement, etc. ${ }^{2}$ Grouping students into small groups in accordance with their wish, giving a project topic for each group: "Means of effective presentation of a scientific text", "Development of skills of independent work of students", "Development of students" critical thinking", "Improvement of a written text" and others. ${ }^{3}$ A teacher acts as a facilitator, tutor coach, supervisor, moderator, and mentor. A teacher-facilitator is not interested in the results of the discussion, does not represent the interests of any of the participating groups and does not participate in the discussion but is responsible for the quality of the tasks. A teacher-tutor provides social and pedagogical support to students in choosing and passing educational programs and helps students to master new activities. A teacher-coach is a coach who is able to make a person a champion; that is, to raise a winner. A teacher-supervisor organizes the work that requires participants to perform actions on a particular program, monitors the correctness of such a program the role of a teacher-supervisor is to combine the functions of an objective observer and an organizer interested in performing a specific task. A teacher-moderator organizes group work, which activates and regulates the process of interaction of participants on the basis of democratic principles, provides business communication, a recording of the discussion process, and the intermediate and final results of the group discussion. A teacher-mentor establishes the intensity and direction of study, reveals the potential of the talent, develops the creativity of students, and encourages students with low success rates. ${ }^{4}$ In accordance with the conditions of anti-epidemic measures aimed at preventing the spread of the COVID-19 pandemic, certain rules in the learning process were established at the university: training in a group of no more than 10 people, and distance learning using Skype, Zoom, Viber communication, Google Classroom email and web resources (personal sites of teachers, websites of departments). When the epidemiological situation improved, the students studied offline. Under such conditions, it was necessary to follow the rules, and to adapt from online learning to offline learning. To provide psychological support, the university organized a psychological assistance service in which qualified specialists and psychologists participated. In addition, teachers supported students and motivated them by personal example. At the same time, the requirements for the tasks of the educational program were the same for both online and offline learning.

\section{Discussion}

Distance learning technologies are developing rapidly all over the world and are a promising tool for Ukraine to provide educational services. Teachers of distance courses must have universal training, they must know how to use modern pedagogical and information technologies, and be psychologically ready to work with students in a new 
educational and cognitive environment. Thanks to such distance learning tools as discussion forums, e-discussions and mailing lists, a new learning environment can be created in which students feel to be an integral part of the team, which increases their motivation to learn. Teachers must know the methods of creating and maintaining such learning environments and develop strategies for interactions between participants in the learning process, as well as increase creative activity and their own skills.

The problem for students is that they do not always have access to the internet and the desire to study and work independently. This is very important, because the effectiveness of the whole learning process depends on these factors. Many students have problems with self-organization. There are still questions about the quality of indicators of this process; the effectiveness, immediacy, and comprehensiveness of software and leading educational technologies. In this context, it is worth thinking about the steps needed to create proper conditions and opportunities. It is necessary to introduce advanced training courses for teachers on mastering virtual learning environments, and to support the development and implementation of e-learning tools (e-textbooks, video content, online tests, etc.) at the state level.

The Zoom program proved to be the most effective and most convenient. However, there were also several disadvantages: the participant needs to join several times, because only $40 \mathrm{~min}$ are provided free of charge for a conference, and this creates an inconvenience. Another problem was that the websites of departments occasionally did not load properly. Often, when many students and teachers were online, the site was knocked out and there was no access to it.

The biggest problem was the instability of the internet connection and a lack of computer skills. However, the development of technology and the improvement of distance learning are moving forward, and in the future, a distant form of learning is quite possible and those students who like it will learn not in person but remotely. It may be also convenient for those who combine work and study or who are abroad but study in Ukraine. There are many benefits and conveniences of distance learning.

Having conducted the research, we distinguished another issue: digital skills to work with technical teaching tools [21]. Most students acquired these skills whilst studying at secondary schools; however, there were those who had considerable difficulties whilst connecting to Zoom and working in Moodle. Evidently, the problem of developing digital skills requires further research.

\section{Conclusions}

During the COVID-19 pandemic, blended learning became a dominant form of obtaining education, and developing and forming competencies.

The use of distance learning tools whilst working with students of the Primary Education specialty has the following advantages:

- Students can access knowledge in a convenient and clear (navigation) way;

- The implementation of inclusive education (students with special educational needs can attend distance learning classes; for example, through various platforms for online classes (Skype, Zoom, etc.);

- The elimination of boundaries between full-time and part-time forms of education;

- Psychological adaptation;

- Comfortable and convenient conditions for learning.

During offline learning, the following peculiarities should be emphasized:

- Oral communication with the use of non-verbal means of learning;

- Practical aspects of communicative activity (online lessons should be dedicated to theoretical preparation);

- An increase in creative development, which is of paramount importance for communicative competence (monotonous mechanical and technical movements);

- The development of an emotional culture during lessons. 
Thus, blended learning can be effective in forming and developing the communicative competence of future teachers under the following conditions:

- Teachers should be universally trained; i.e., they should be able to use modern pedagogical and information technologies, and to be psychologically ready to work with students in a new learning environment;

- The stimulation of cooperation strategies between the participants of the learning environment, the enhancement of the creativity of students (methods of critical thinking and emotional intelligence development) as many students find it problematic not having access to the internet and the desire to learn and work independently;

- A practical component of communicative competence, namely, that which presupposes the use of non-verbal means, should be applied during offline lessons;

- The necessity to introduce advanced training courses for teachers on mastering virtual learning environments, and to support the development and implementation of e-learning tools (e-textbooks, video content, online tests, etc.) at the state level.

Author Contributions: Conceptualization, M.B. and O.T.; methodology, H.H.; software, O.D.; validation, O.D., O.T. and M.B.; formal analysis, H.H.; investigation, M.B.; resources, O.D.; data curation, O.T.; writing—original draft preparation, M.B. and O.T.; writing—review and editing, H.H. and O.D.; visualization, H.H.; supervision, O.T.; project administration, O.D.; funding acquisition, M.B. All authors have read and agreed to the published version of the manuscript.

Funding: This research received no external funding.

Institutional Review Board Statement: The study was conducted according to the guidelines of the Declaration of Helsinki, and approved by the Ethics Committee of Commission on internal quality assurance of education in TNPU (protocol code №3 and date of approval 24 May 2021).

Informed Consent Statement: Not applicable.

Data Availability Statement: Data available in a publicly accessible repository.

Conflicts of Interest: The authors declare no conflict of interest.

\section{References}

1. Boyko, M. Criteria and indicators of quality assessment of future professionals training in the system of Ukrainian higher education. J. Educ. Health Sport 2019, 9, 323-330. [CrossRef]

2. ANNEX to the Proposal for a Council Recommendation on Key Competences for Lifelong Learning. Available online: https: / / eur-lex.europa.eu/resource.html?uri=cellar:395443f6-fb6d-11e7-b8f5-01aa75ed71a1.0001.02/DOC_1\&format=PDF (accessed on 17 April 2019).

3. Key Skills of the 21st Century. Available online: https://www.britishcouncil.org.ua/sites/default/files/programa_klyuchovi_ uminnya_21-go_stolittya.pdf (accessed on 17 April 2019).

4. Stavytskyy, A.; Dluhopolskyi, O.; Kharlamova, G.; Karpuk, A.; Osetskyi, V. Testing the fruitfulness of the institutional environment for the development of innovative-entrepreneurial universities in Ukraine. Probl. Perspect. Manag. 2019, 17, 274-288. [CrossRef]

5. Karakose, T.; Yirci, R.; Papadakis, S. Exploring the Interrelationship between COVID-19 Phobia, Work-Family Conflict, FamilyWork Conflict, and Life Satisfaction among School Administrators for Advancing Sustainable Management. Sustainability 2021, 13, 8654. [CrossRef]

6. Fernandes, J.; Costa, R.; Peres, P. Putting Order into Our Universe: The Concept of Blended Learning-A Methodology within the Concept-based Terminology Framework. Educ. Sci. 2016, 6, 15. [CrossRef]

7. Vatuitniev, M. Communicativeness of teaching Russian in schools abroad. Rus. Yazyk Za Rub. 1977, 6, $38-45$.

8. Fedorenko, Y.S. Communicative competence as the most crucial element of successful communication. Ridna Shkola 2002, 1, 63-65.

9. Boyko, M.; Dluhopolskyi, O. Academic integrity in Ukrainian universities: Case of academic IQ project in TNPU. MEST J. 2021, 9, 1-6. [CrossRef]

10. Lomakovytch, S.; Tereschenko, V.; Lukianchuk, T.; Korniichuk, V. Verbal-communicative competence a person: Dimensions and measurements. Visnyk. Testuvannia Monit. Osv. 2011, 1, 4-11.

11. Chomsky, N. Language and Thinking; Moscow State University: Moscow, Russia, 1972.

12. Hez, N. Formation of communicative competence as the object of foreign methodological research. Inostr. Yazyki Shkolie $1985,2,7-24$.

13. Hymes, D. Two types of linguistic relativity. In Sociolinguistics; Bright, W., Ed.; Mouton: The Hague, The Netherlands, 1966; pp. 114-158. 
14. Izarenkov, D.I. Essential components of communicative competence and their formation at the advanced stage of training of students of non-philological specialties. Rus. Yazyk Za Rub. 1990, 4, 54-60.

15. Kazartseva, O. Culture of Speech Communication: Theory and Practice; Flint: Moscow, Russia, 1999.

16. Savignon, S. Evolution of Communicative Competence: The ACTFL Provisional Proficiency Guidelines. Mod. Lang. J. 1995, 95, 129-134.

17. Chomsky, N. Aspects of the Theory of Syntax; Cambridge University Press: Cambridge, UK, 1965.

18. Dmytrenko, K.A.; Konovalova, M.V.; Semivolos, O.P.; Beketova, S.V. Common Forms of Work—New Approach: Developing Key Competencies; Osnova: Kharkiv, Ukraine, 2018; 119p.

19. Turko, O.; Kravchuk, T.; Kashuba, O.; Navolska, H.; Kutsyi, I. The Latest Tools for the Formation of Foreign Language Communicative Competence of Students of Non-language Specialties. Arab. World Engl. J. (AWEJ) 2021, 12, 443-457. [CrossRef]

20. Cronbach, L.J. Coefficient alpha and the internal structure of tests. Psychometrika 1951, 16, 297-334. [CrossRef]

21. Poultsakis, S.; Papadakis, S.; Kalogiannakis, M.; Psycharis, S. The management of Digital Learning Objects of Natural Sciences and Digital Experiment Simulation Tools by teachers. Adv. Mob. Learn. Educ. Res. 2021, 1, 58-71. [CrossRef] 